\title{
The dye-sensitized solar cell database
}

\author{
Vishwesh Venkatraman*, Rajesh Raju, Solon P. Oikonomopoulos and Bjørn K. Alsberg
}

\begin{abstract}
Background: Dye-sensitized solar cells (DSSCs) have garnered a lot of attention in recent years. The solar energy to power conversion efficiency of a DSSC is influenced by various components of the cell such as the dye, electrolyte, electrodes and additives among others leading to varying experimental configurations. A large number of metalbased and metal-free dye sensitizers have now been reported and tools using such data to indicate new directions for design and development are on the rise.

Description: DSSCDB, the first of its kind dye-sensitized solar cell database, aims to provide users with up-to-date information from publications on the molecular structures of the dyes, experimental details and reported measurements (efficiencies and spectral properties) and thereby facilitate a comprehensive and critical evaluation of the data. Currently, the DSSCDB contains over 4000 experimental observations spanning multiple dye classes such as triphenylamines, carbazoles, coumarins, phenothiazines, ruthenium and porphyrins.

Conclusion: The DSSCDB offers a web-based, comprehensive source of property data for dye sensitized solar cells. Access to the database is available through the following URL: www.dyedb.com.
\end{abstract}

Keywords: Dye sensitized solar cells, Database

\section{Background}

With renewable energy-based systems gaining momentum, there has been intense focus on harnessing energy from the sun while making it useable and cost-effective. Solar cell technologies that convert sunlight into electricity include those based on silicon, polymer, quantum dots, dye-sensitized and more recently, perovskites. Among these dye-sensitized solar cells (DSSCs) also known as Grätzel cells have received a lot of attention [1, 2]. In recent years, this field has seen a dramatic increase in published research. An ISI Web of Knowledge search for the term "dye-sensitized solar cells" yielded more than 18,000 articles spanning years 1991-2017 (see Fig. 1) with a significant proportion published in the last 5-10 years.

The DSSC typically consists of a monolayer of a photosensitive dye that is adsorbed on a mesoporous oxide layer (such as $\mathrm{TiO}_{2}, \mathrm{ZnO}$ or $\mathrm{SnO}_{2}$ ) that is deposited on a transparent conductive glass substrate, a redox electrolyte (iodide or cobalt-based) and a platinized counter electrode. On excitation (absorption of incoming light),

\footnotetext{
*Correspondence: vishwesh.venkatraman@ntnu.no Department of Chemistry, NTNU, Høgskoleringen, 7491 Trondheim, Norway
}

electrons from the dye diffuse (flow of current) through the semiconductor and move on to the back collecting electrode. Dye regeneration takes place through electron donation from the electrolyte aided by the catalyst in the counter electrode. The modular architecture of the DSSC thus enables functions such as electron transport, light absorption and hole transport to be handled separately $[1,2]$.

Although DSSC efficiencies have been improving, the pace of these improvements has been somewhat slow, with an increase of only 6\% [3] from a value of $7.1 \%$ in 1991 [4]. The variations in the power conversion efficiencies (PCE) for different DSSCs can be attributed to changes in the cell architecture and fabrication [5-8]. While a significant amount of these efforts have been devoted to molecular engineering of the dye sensitizer [9-13], others have focused on the optimization of the electrodes [14, 15] and electrolytes [16-18] along with factors such as the concentrations of the solvent baths during sensitization [19], and the size and thickness of photoanodes $[8,20,21]$.

The DSSC efficiency is influenced by a number of components/parameters. Other than the dye one can add a cosensitizer to account for the higher wavelength regions, 


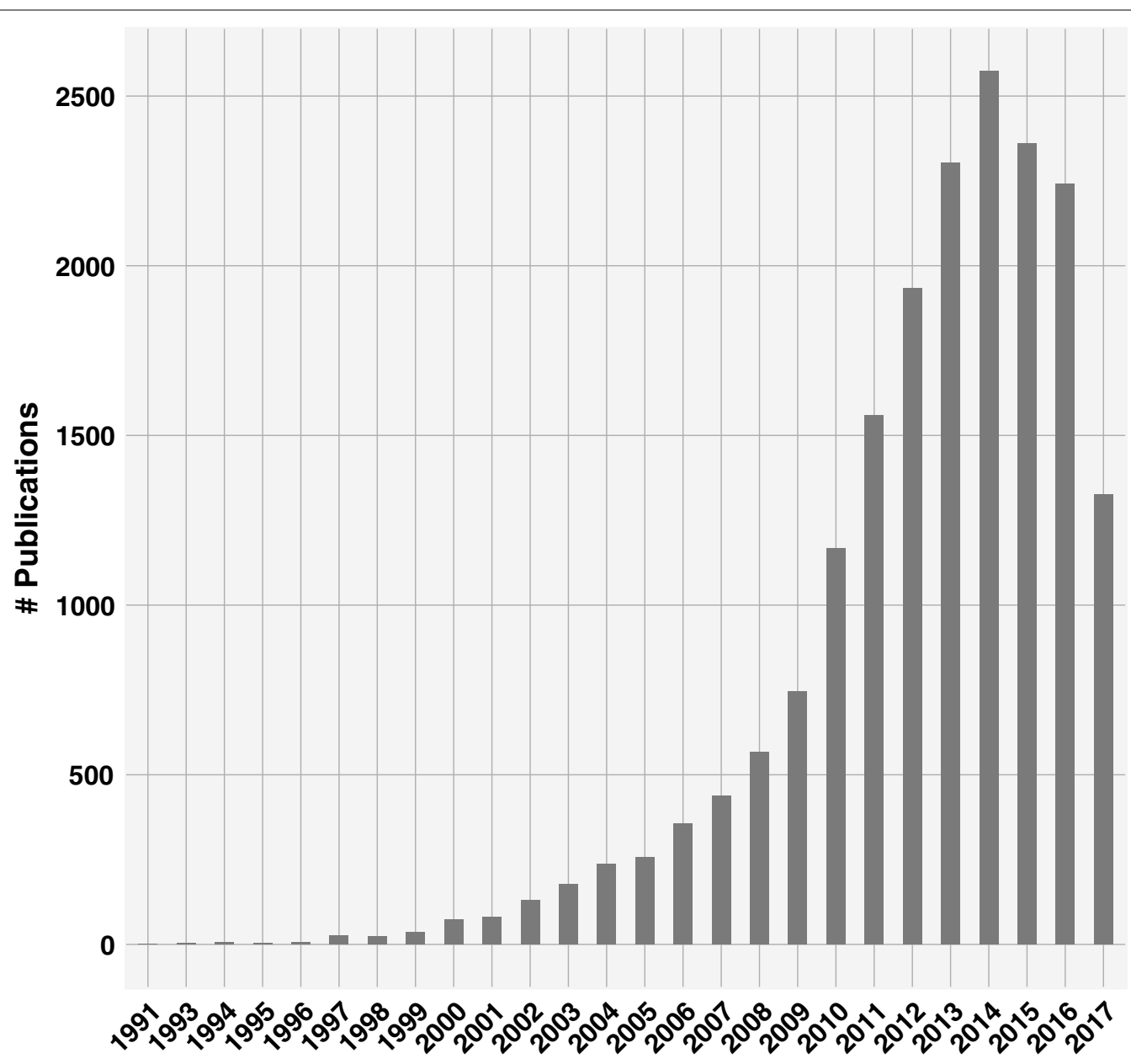

Fig. 1 Literature growth of dye sensitized solar cells. The graph was produced by performing a Web of Science search for the keywords "dye sensitized solar cells" and restricting the search to articles in English. In addition subject areas such as mechanics, toxicology, pharmacology and educational research were also excluded to yield around 18445 records

use agents like chenodeoxycholic acid (CDCA) to reduce aggregation and also change the electrolyte from iodide to cobalt which has often resulted in increased PCEs. Other factors such as the dye bath and concentrations also have an impact on the PCEs. Modifications to the structure of the dye sensitizer in particular have been found to be the most widely applied method to improve device efficiencies. Given that, by introducing systematic variations of the substituent groups in the dye can improve the light harvesting and electron injection capabilities among other properties, various classes of dyes (metal-free and inorganic-based) have been investigated ranging from coumarins, carbazoles, indolines, triphenylamines [10], phenothiazines [9], fulvalenes [22] to ruthenium [23] and porphyrin-based [24] sensitizers.

Dye materials discovery has been largely based on serendipity or iterative chemical substitution. Given the demand for methodologies that can accelerate the design of molecular materials with tailored properties, cheminformatics (or materials informatics) based frameworks for high-throughput screening of candidate structures have been proposed: dyes [25], solid state metal oxide photovoltaic cells [26] and organic photovoltaics [27, 28]. With a view to understanding how structural/chemical modifications impact the solar cell performances, recent efforts have focused on creating quantitative structure property relationships $[26,29-36]$ that establish a mathematical relationship between various molecular structure descriptors and a solar cell property of interest such as the PCE. The models produced in this process have been further used to direct the search for promising dyes/ photvoltaic materials that satisfy desirable criteria [26, 37-39]. Informatics approaches have also been recently 
applied to the identification of suitable photocathode materials [40] and solid state electrolytes [41].

Recently, a number of data repositories such as the Materials Project [42], Khazana [43], the Harvard Organic Photovoltaic Dataset [44], and the Open Spectral Database [45] have emerged that facilitate the discovery of qualitative/quantitative rules, which can be used to guide materials design. Here, we report the Dye Sensitized Solar Cell Database (DSSCDB) consisting of experimental results compiled from the literature. The database is intended as a central repository for sharing photovoltaic performance related data and should be of broad interest to scientists in photovoltaics, quantum chemistry, chemometrics and related disciplines. Search tools have been implemented with both text and structure-based functionalities.

\section{Description and utility}

Information regarding the dyes was manually retrieved from journal articles obtained using keyword ("dye sensitized solar cells", "triphenylamines" etc.) searches on the ISI Web of Knowledge. For each dye, the following data has been recorded:

1. DOI: the digital object identifier for the referenced article

2. Performance parameters: open circuit voltage $\left(V_{o c}\right.$ in $\mathrm{mV})$, short circuit current $\left(J_{s c} \mathrm{in} \mathrm{mA} / \mathrm{cm}^{2}\right)$, fill factor $(\mathrm{FF})$, power conversion efficiency (PCE)

3. Electrolyte: nature of redox electrolyte (iodide/ cobalt-based) and the composition

4. Active area of the cell (in $\mathrm{cm}^{2}$ )

5. Coadsorbents such as chenodeoxycholic acid (CDCA) and their concentration if used

6. Cosensitizer if used

7. Semiconductor: the kind of semiconductor layer $\left(\mathrm{TiO}_{2}, \mathrm{ZnO}\right.$ etc.) used and their thickness (in $\mu \mathrm{m}$ ) along with any scattering used

8. Dye loading: the amount of dye adsorbed on the semiconductor film (in $\mathrm{nmol} / \mathrm{cm}^{2}$ )

9. Exposure time: the sensitizer adsorption time

10. Solar simulator conditions such as the light intensity (typically AM 1.5G, $100 \mathrm{~mW} / \mathrm{cm}^{2}$ ) used

11. DSSC comments: general information relating to the type of the DSSC (solid state, p-type), the dye bath used and other details such as the surface treatment for the semiconductor or electrodes

12. SMILES, InChi: SMILES notation for the chemical structure and the corresponding IUPAC International Chemical Identifier (InChi) key

13. The absorption and emission maxima and the solvent used in the experiment
14. Dye class: to indicate the type of the donors or specific chemical groups in order to enable a keywordbased search.

The database is centred around 4 main tables (see Fig. 2) reflecting the aforementioned details. During the data collection, articles without a valid DOI and those with incomplete performance data were excluded. The 2D structures of the dyes were drawn using various molecular drawing software. For cases where the chemical names were available, the SMILES formats were generated using OPSIN [46], failing which the structures were drawn by hand. Corresponding InChi keys were then generated using OpenBabel $[47,48]$. Images of the structures have been generated using the Indigo Toolkit [49]. The web interface has been designed using the Django 1.10 MVC framework (https://www.djangoproject.com) and connected to a PostgresSQL [50] database and hosted on the Amazon Cloud Platform. The package manager Conda 4.3.6 (https://www.conda.io) was used to include RD-Kit 2017.03.1 [51] and PyBel [52] support. The Docker platform (https://www.docker.com/) was additionally used to facilitate continuous development and ease of deployment.

\section{Search and retrieval}

The entire database can downloaded as a csv file which contains SMILES, InChi, performance data, experimental conditions, chemical scaffold type, and links to the articles from which the data was sourced. Data can be retrieved using either a range search based on options such as the PCE, FF, $J_{s c}, V_{o c}$ or alternatively performing a free text search for specific dye classes (see Fig. 3). A search for triphenylamines for instance yields more than 1600 results. For each structure, the class of the dye (triphenylamine, coumarin etc.) have been recorded which facilitates the search for specific dyes. Structure-based searches (drawn using the JSME Molecular Editor [53]) can be carried out using either fingerprint-based Tanimoto similarity or SMARTS-based substructure matching, functions for which are available in the Pybel library [52]. The results are presented in a table with details for each entry provided in a separate page. The structure can be visualized as a $2 \mathrm{D}$ diagram or alternatively in three dimensions using the WebGL based 3dmol library [54]. For cases, where multiple results are available for the same structure, links to related entries are provided.

\section{Uploading data}

To contribute to the DSSCDB, users are firstly required to register themselves. Data for the dyes can be entered in two ways. While single entries can be entered using the web interface (see Fig. 4), an Excel file containing 


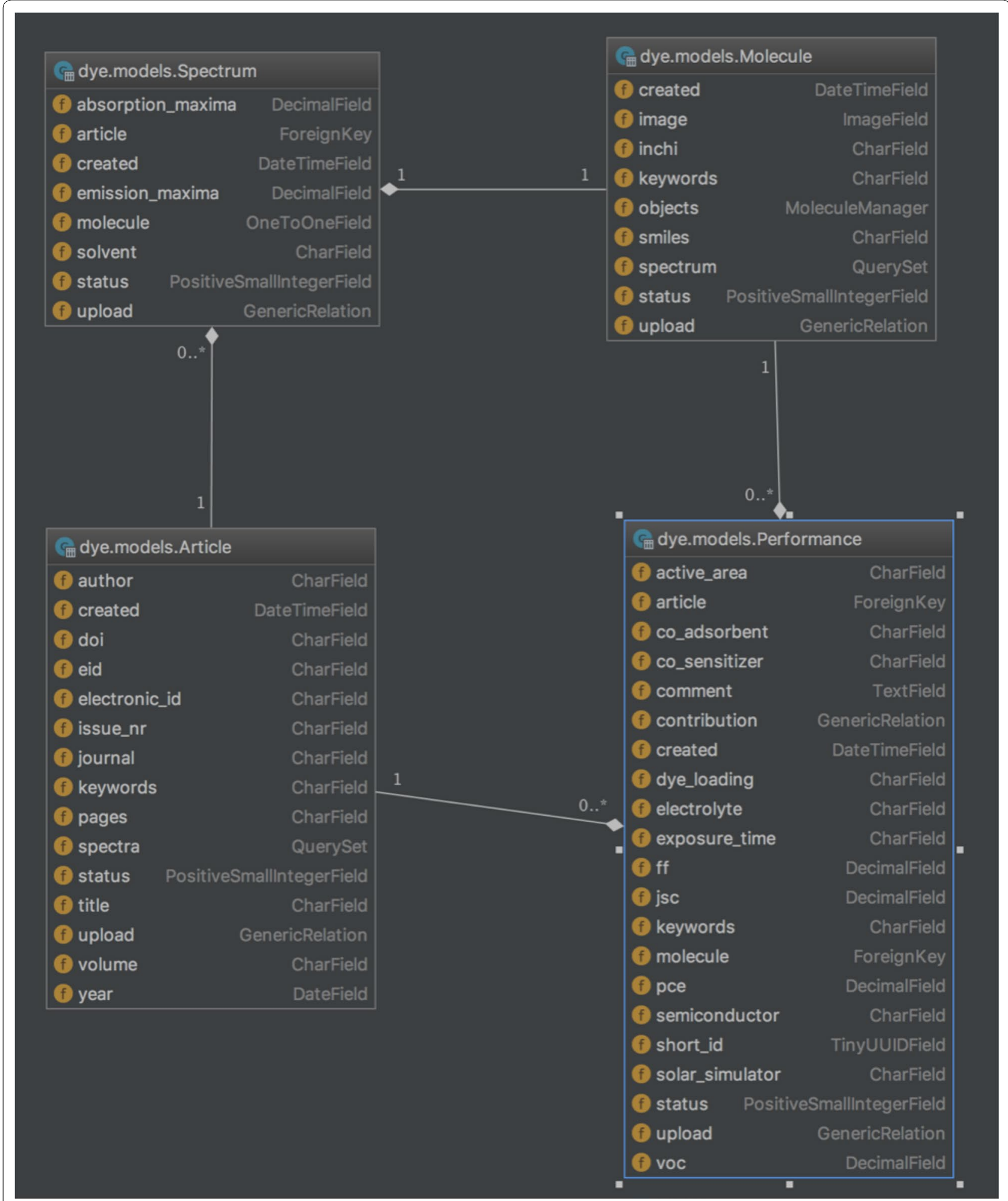

Fig. 2 Database structure. Schematic representation of the DSSCDB 


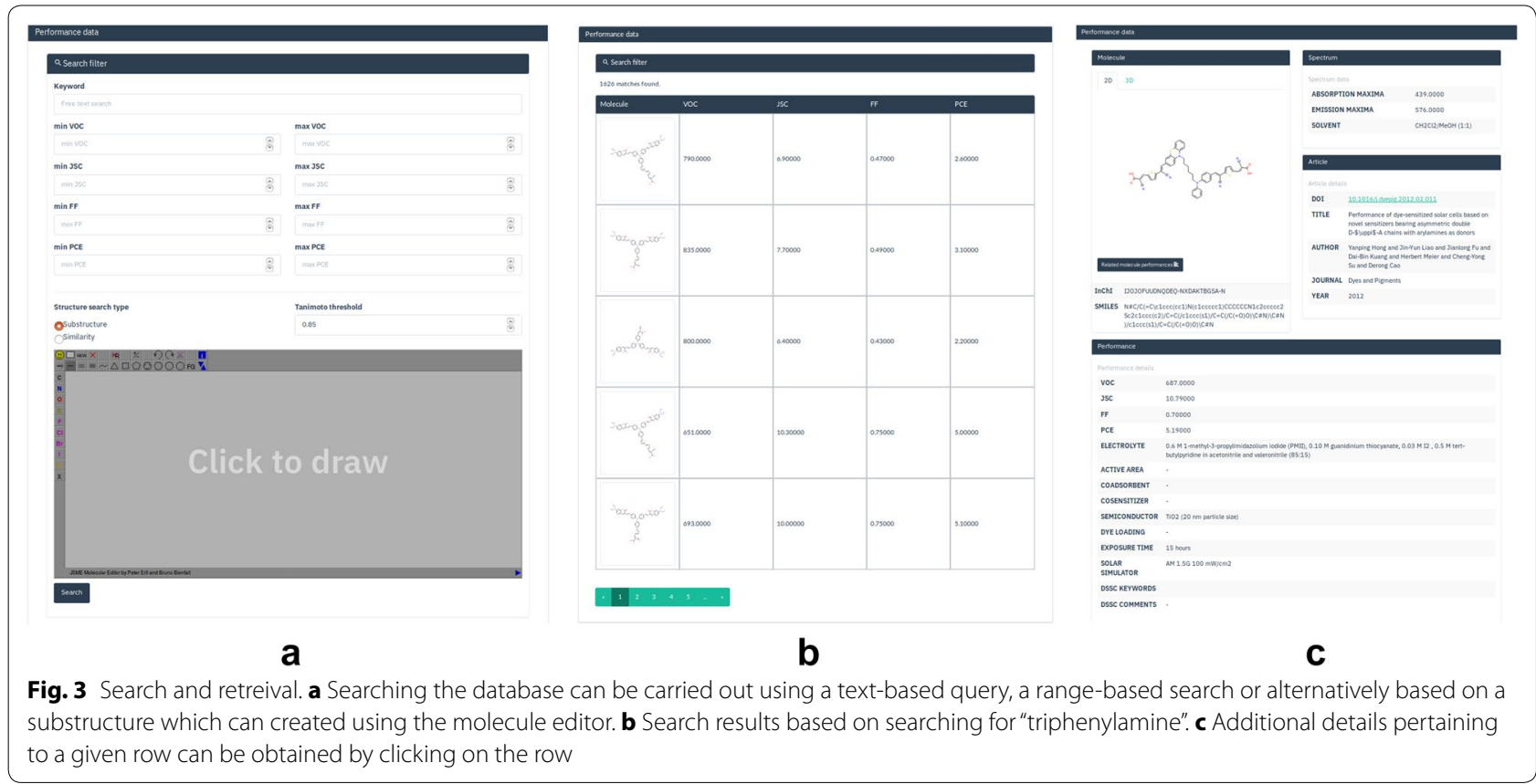

the columns to be filled can be used for multiple entries (template available as part of the supplementary information). The uploaders are required to provide the molecular structure information (valid SMILES and InChi codes), performance data, experimental conditions, chemical scaffold (coumarin, porphyrin etc.) and the digital object identifier for the article from which the data was collected. In order to ensure the validity of the data entered, a verification step has been added whereby the database administrators can confirm the authenticity of the data.

\section{Data summary}

The database currently holds over 4000 experimental results spanning a diverse set of metal-free and metal complex dyes. Metal-free sensitizers are dominant in the database among which triphenylamines form the most prominent class. Figure 5 offers a visual summary of the reported efficiencies for the different dye classes.

In many articles, device performances based on new dyes being tested are compared with what has been frequently referred to as a benchmark/reference dye which is typically a Ruthenium dye commonly known as N719. Querying "N719" on the DSSCDB yields around 329 results collated from over 250 articles. The reported efficiencies which range between 2 and $11 \%$ for these records are summarized in Fig. 6. Active areas and the thickness of the semiconductor layer are often the most varied parameters in many studies. The impact of this variation can be studied in terms of $2 \mathrm{D}$ histograms shown in Fig. 6b, c respectively. Here, the hexagons coloured in shades of red indicate the count of the combinations. For instance, it is seen that areas around $0.16-0.20 \mathrm{~cm}^{2}$ have average efficiencies of around $7-8 \%$ in more than 30 cases, while a thickness of around $16-18 \mu \mathrm{m}$ for the $\mathrm{TiO}_{2}$ layer yielding similar efficiencies is seen for 25 or more cases. However, as can be seen from the plots, there are also other settings that can lead to lower or higher values.

Given that, such subtle changes can lead to an increase or decrease in the efficiency, how much of this improvement is real and significant is difficult to ascertain. From a data analysis perspective, particularly for QSPR modelling, identifying observations with comparable experimental criteria poses significant challenges. The need for proper characterization and standardization of measurement protocols has been highlighted in a number of publications [55-57]. Although seeking confirmation from independent certification laboratories, very few publications report such steps. We hope that in due course, the best-practice characterization procedures can be adopted. 


\section{Upload record}

DoI

DOI

SMILES

INCHI

SMILES

Benzene: $\mathrm{C} 1=\mathrm{CC}=\mathrm{CC}=\mathrm{C} 1$

INCHI

Keywords

Keywords

Absorption maxima

Absorption maxima

[nm]

Solvent

Solvent

VOC

VOC

$[\mathrm{mV}]$

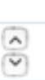

JSC

JSC

$\left[\mathrm{mA} / \mathrm{cm}^{\wedge} 2\right]$

\section{Electrolyte}

Electrolyte

Active area

Active area

[cm2]

Co adsorbent

Co adsorbent

Semiconductor

Semiconductor

Exposure time

Exposure time

\section{Comment}

Comment

Upload

Fig. 4 Single data entry. The web interface to enter single records
FF

$\hat{\imath}$

FF

Emission maxima

ิ

(ิ)

PCE

$\hat{\sim}$

PCE

\%, 0-1
Co sensitizer

Dye loading

Dye loading

[nmol/cm2]

Solar simulator

AM $1.5 \mathrm{~g}$ 


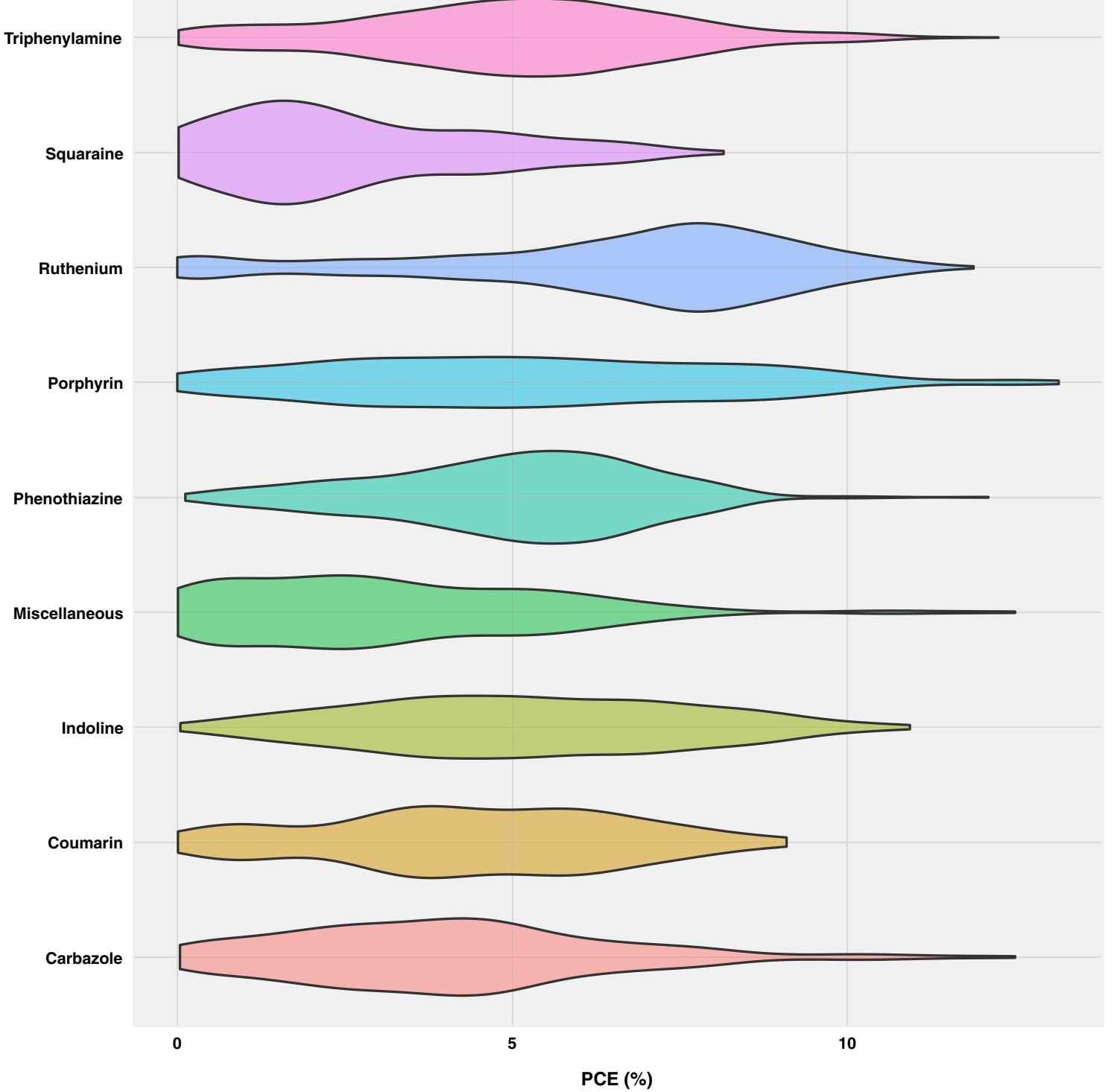

Fig. 5 Compound classes and efficiency ranges in the DSSCDB. Violin plots showing the distribution of the efficiencies. Values in the wider parts of the violin are more probable than those in narrower regions. The "Miscellaneous" class includes dyes based on donors such as perylene, azobenzene, anthracene, fulvalene, imidazole and julolidine

\section{Conclusions}

A first of its kind database for dye sensitized solar cells is described. The repository offers an at a glance summary of the experimental conditions that led to the reported efficiencies and properties and is expected to be an important asset for scientists and researchers in the field of photovoltaics and associated fields. It is our hope that the database can be used to extend knowledge and stimulate new directions for design and development of photovoltaic materials. We anticipate expanding and updating 

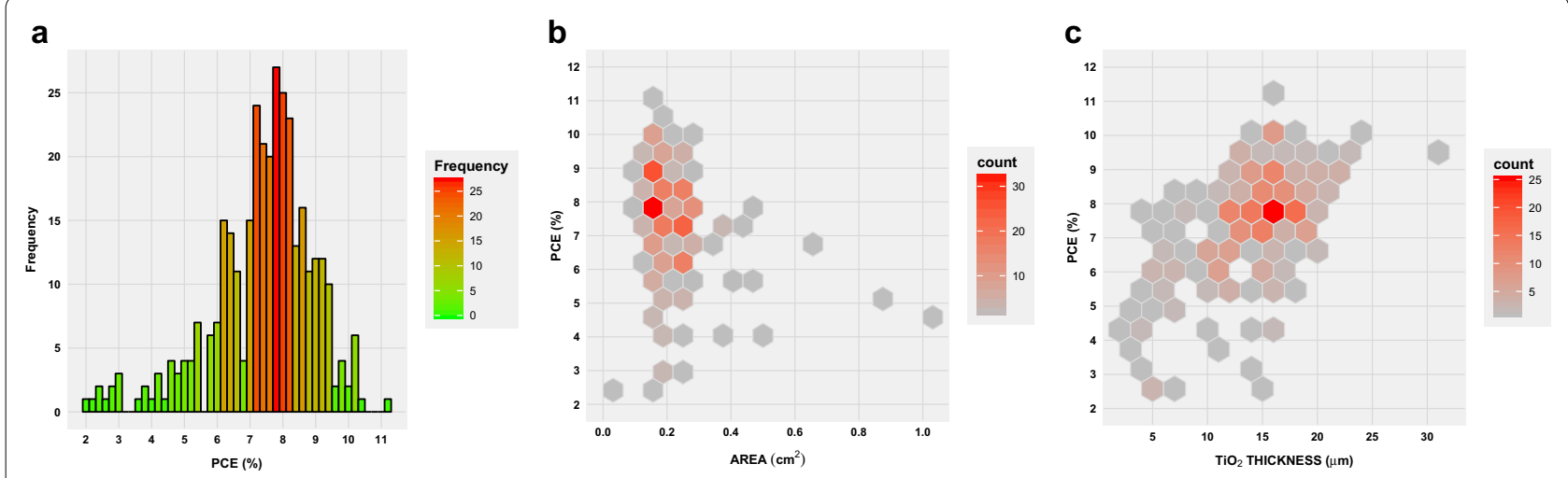

Fig. 6 Summary of efficiencies for the reference dye Ruthenium N719. a Chart shows the distribution of the reported efficiencies (over 300 cases) for N719. $\mathbf{b} 2 \mathrm{D}$ histogram of the PCE versus the active area of the device, c $2 \mathrm{D}$ histogram of the PCE versus the thickness of the $\mathrm{TiO}_{2}$ layer used

this collection over time and further extend the database to dyes used in other fields such as light emitting diodes, food products etc.

\section{Additional files}

Additional file 1: Full search criteria used on the Web of Science.

Additional file 2: Excel file template for uploading data.

\section{Authors' contributions}

W along with the late Prof. Bjørn Alsberg (BKA) conceived the database. W performed the data curation and created the framework for the database. RR and SPO helped in the data curation. VV drafted the manuscript with assistance from RR and SPO. All authors read and approved the final manuscript.

\section{Acknowledgements}

This article is dedicated to Prof. Bjørn Alsberg, respected friend and colleague, who passed away shortly after submission.

\section{Competing interests}

The authors declare that they have no competing interests.

\section{Availability and requirements}

The database can be accessed at www.dyedb.com. The source code associated with the database and web interface is available at https://github.com/ Simensen-Hambro/DSSCDB. The software and data are released under the Academic Free License.

\section{Ethics approval and consent to participate}

Not applicable.

\section{Funding}

This work was supported through a grant (Grant No. 90221900) from the Research Council of Norway (RCN).

\section{Publisher's Note}

Springer Nature remains neutral with regard to jurisdictional claims in published maps and institutional affiliations.

Received: 4 December 2017 Accepted: 25 March 2018 Published online: 03 April 2018

\section{References}

1. Hagfeldt A, Boschloo G, Sun L, Kloo L, Pettersson H (2010) Dye-sensitized solar cells. Chem Rev 110(11):6595-6663

2. Clifford JN, Martínez-Ferrero E, Viterisi A, Palomares E (2011) Sensitizer molecular structure-device efficiency relationship in dye sensitized solar cells. Chem Soc Rev 40(3):1635-1646

3. Kakiage K, Aoyama Y, Yano T, Oya K, Kyomen T, Hanaya M (2015) Fabrication of a high-performance dye-sensitized solar cell with 12.8\% conversion efficiency using organic silyl-anchor dyes. Chem Commun 51(29):6315-6317

4. O'Regan B, Grätzel M (1991) A low-cost, high-efficiency solar cell based on dye-sensitized colloidal $\mathrm{TiO}_{2}$ films. Nature 353(6346):737-740

5. Ye M, Wen X, Wang M, locozzia J, Zhang N, Lin C, Lin Z (2015) Recent advances in dye-sensitized solar cells: from photoanodes, sensitizers and electrolytes to counter electrodes. Mater Today 18(3):155-162

6. Gong J, Sumathy K, Qiao Q, Zhou Z (2017) Review on dye-sensitized solar cells (DSSCs): advanced techniques and research trends. Renew Sustain Energy Rev 68:234-246

7. Sugathan V, John E, Sudhakar K (2015) Recent improvements in dye sensitized solar cells: a review. Renew Sustain Energy Rev 52:54-64

8. Lee C-P, Li C-T, Ho K-C (2017) Use of organic materials in dye-sensitized solar cells. Mater Today 20(5):267-283

9. Huang Z-S, Meier H, Cao D (2016) Phenothiazine-based dyes for efficient dye-sensitized solar cells. J Mater Chem C 4(13):2404-2426

10. Mahmood A (2016) Triphenylamine based dyes for dye sensitized solar cells: a review. Sol Energy 123:127-144

11. Higashino T, Imahori H (2015) Porphyrins as excellent dyes for dyesensitized solar cells: recent developments and insights. Dalton Trans 44(2):448-463

12. Li X, Zhang X, Hua J, Tian H (2017) Molecular engineering of organic sensitizers with o, p-dialkoxyphenyl-based bulky donors for highly efficient dye-sensitized solar cells. Mol Syst Des Eng 2(2):98-122

13. Meier H, Huang Z-S, Cao D (2017) Double d-pi-a branched dyes: a new class of metal-free organic dyes for efficient dye-sensitized solar cells. J Mater Chem C 5(38):9828-9837

14. Thomas S, Deepak TG, Anjusree GS, Arun TA, Nair SV, Nair AS (2014) A review on counter electrode materials in dye-sensitized solar cells. J Mater Chem A 2(13):4474-4490

15. Gao C, Han Q, Wu M (2017) Review on transition metal compounds based counter electrode for dye-sensitized solar cells. J Energy Chem

16. Wu J, Lan Z, Lin J, Huang M, Huang Y, Fan L, Luo G (2015) Electrolytes in dye-sensitized solar cells. Chem Rev 115(5):2136-2173

17. Su'ait MS, Rahman MYA, Ahmad A (2015) Review on polymer electrolyte in dye-sensitized solar cells (DSSCs). Sol Energy 115:452-470

18. Bella F, Gerbaldi C, Barolo C, Grätzel M (2015) Aqueous dye-sensitized solar cells. Chem Soc Rev 44(11):3431-3473 
19. Pazoki M, Lohse PW, Taghavinia N, Hagfeldt A, Boschloo G (2014) The effect of dye coverage on the performance of dye-sensitized solar cells with a cobalt-based electrolyte. Phys Chem Chem Phys 16(18):8503

20. Sulaeman U, Abdullah AZ (2017) The way forward for the modification of dye-sensitized solar cell towards better power conversion efficiency. Renew Sustain Energy Rev 74:438-452

21. Balasingam SK, Lee M, Kang MG, Jun Y (2013) Improvement of dyesensitized solar cells toward the broader light harvesting of the solar spectrum. Chem Commun 49(15):1471-1487

22. Duvva N, Chilakamarthi U, Giribabu L (2017) Recent developments in tetrathiafulvalene and dithiafulvalene based metal-free organic sensitizers for dye-sensitized solar cells: a mini-review. Sustain Energy Fuels 1(4):678-688

23. Yin J-F, Velayudham M, Bhattacharya D, Lin H-C, Lu K-L (2012) Structure optimization of ruthenium photosensitizers for efficient dyesensitized solar cells: a goal toward a "bright" future. Coord Chem Rev 256(23-24):3008-3035

24. Li L-L, Diau EW-G (2013) Porphyrin-sensitized solar cells. Chem Soc Rev 42(1):291-304

25. Cole JM, Low KS, Ozoe H, Stathi P, Kitamura C, Kurata H, Rudolf P Kawase T (2014) Data mining with molecular design rules identifies new class of dyes for dye-sensitised solar cells. Phys Chem Chem Phys 16(48):26684-26690

26. Borvick E, Anderson AY, Barad H-N, Priel M, Keller DA, Ginsburg A, Rietwyk KJ, Meir S, Zaban A (2017) Process-function data mining for the discovery of solid-state iron-oxide PV. ACS Comb Sci 19(12):755-762

27. Hachmann J, Olivares-Amaya R, Jinich A, Appleton AL, Blood-Forsythe MA, Seress LR, Román-Salgado C, Trepte K, Atahan-Evrenk S, Er S, Shrestha S, Mondal R, Sokolov A, Bao Z, Aspuru-Guzik A (2014) Lead candidates for high-performance organic photovoltaics from high-throughput quantum chemistry: the Harvard clean energy project. Energy Environ Sci 7(2):698-704

28. Hachmann J, Olivares-Amaya R, Atahan-Evrenk S, Amador-Bedolla C, Sánchez-Carrera RS, Gold-Parker A, Vogt L, Brockway AM, Aspuru-Guzik A (2011) The harvard clean energy project: large-scale computational screening and design of organic photovoltaics on the world community grid. J Phys Chem Lett 2(17):2241-2251

29. Venkatraman V, Åstrand P-O, Alsberg BK (2014) Quantitative structureproperty relationship modelling of grätzel solar cell dye. J Comput Chem 35(3):214-226

30. Venkatraman V, Alsberg BK (2015) A quantitative structure-property relationship study of the photovoltaic performance of phenothiazine dyes. Dyes Pigment 114:69-77

31. Ip CM, Eleuteri A, Troisi A (2014) Predicting with confidence the efficiency of new dyes in dye sensitized solar cells. Phys Chem Chem Phys 16(36):19106

32. Tortorella S, Marotta G, Cruciani G, De Angelis F (2015) Quantitative structure-property relationship modeling of ruthenium sensitizers for solar cells applications: novel tools for designing promising candidates. RSC Adv 5:23865-23873

33. Li H, Zhong Z, Li L, Gao R, Cui J, Gao T, Hu LH, Lu Y, Su Z-M, Li H (2015) A cascaded QSAR model for efficient prediction of overall power conversion efficiency of all-organic dye-sensitized solar cells. J Comput Chem 36(14):1036-1046

34. Kar S, Roy J, Leszczynska D, Leszczynski J (2016) Power conversion efficiency of arylamine organic dyes for dye-sensitized solar cells (DSSCs) explicit to cobalt electrolyte: understanding the structural attributes using a direct QSPR approach. Computation 5(1):2

35. Madugula SS, Yarasi S (2017) Molecular design of porphyrin dyes for dye sensitized solar cells: a quantitative structure property relationship study. Int J Quant Chem 117(14):25385

36. Kaspi O, Yosipof A, Senderowitz H (2017) RANdom SAmple Consensus (RANSAC) algorithm for material-informatics: application to photovoltaic solar cells. J Cheminf 9(1):34

37. Venkatraman V, Foscato M, Jensen VR, Alsberg BK (2015) Evolutionary de novo design of phenothiazine derivatives for dye-sensitized solar cells. $J$ Mater Chem A 3:9851-9860

38. Venkatraman $V$, Abburu S, Alsberg BK (2015) Artificial evolution of coumarin dyes for dye sensitized solar cells. Phys Chem Chem Phys 17(41):27672-27682
39. Kar S, Roy JK, Leszczynski J (2017) In silico designing of power conversion efficient organic lead dyes for solar cells using todays innovative approaches to assure renewable energy for future. npj Comput Mater $3(1): 22$

40. Moot T, Isayev O, Call RW, McCullough SM, Zemaitis M, Lopez R, Cahoon JF, Tropsha A (2016) Material informatics driven design and experimental validation of lead titanate as an aqueous solar photocathode. Mater Discov 6:9-16

41. Kireeva N, Pervov VS (2017) Materials space of solid-state electrolytes: unraveling chemical composition-structure-ionic conductivity relationships in garnet-type metal oxides using cheminformatics virtual screening approaches. Phys Chem Chem Phys 19(31):20904-20918

42. Jain A, Ong SP, Hautier G, Chen W, Richards WD, Dacek S, Cholia S, Gunter D, Skinner D, Ceder G, Persson KA (2013) Commentary: The materials project: a materials genome approach to accelerating materials innovation. APL Mater 1(1):011002

43. Huan TD, Mannodi-Kanakkithodi A, Kim C, Sharma V, Pilania G, Ramprasad $R$ (2016) A polymer dataset for accelerated property prediction and design. Sci Data 3:160012

44. Lopez SA, Pyzer-Knapp EO, Simm GN, Lutzow T, Li K, Seress LR, Hachmann J, Aspuru-Guzik A (2016) The harvard organic photovoltaic dataset. Sci Data 3:160086

45. Chalk SJ (2016) The open spectral database: an open platform for sharing and searching spectral data. J Cheminf 8(1):55

46. Lowe DM, Corbett PT, Murray-Rust P, Glen RC (2011) Chemical name to structure: OPSIN, an open source solution. J Chem Inf Model 51(3):739-753

47. O'Boyle NM, Banck M, James CA, Morley C, Vandermeersch T, Hutchison GR (2011) Open babel: an open chemical toolbox. J Cheminf 3(1):33

48. O: OpenBabel 2.4.1 (2017). http://www.openbabel.org

49. EPAM Systems I (2009-2014) Indigo-depict. http://lifescience.opensource. epam.com/indigo/indigo-depict.html

50. Group PGD (2017) PostgreSQL version 9.5.9. https://www.postgresql.org/

51. Landrum G (2017) RDKit: open-source cheminformatics. http://www. rdkit.org

52. O'Boyle NM, Morley C, Hutchison GR (2008) Pybel: a python wrapper for the OpenBabel cheminformatics toolkit. Chem Cent J 2(1):5

53. Bienfait B, Ertl P (2013) JSME: a free molecule editor in JavaScript. J Chem$\inf 5(1): 24$

54. Rego N, Koes D (2014) 3Dmol.js: molecular visualization with WebGL. Bioinformatics 31(8):1322-1324

55. Snaith HJ (2012) The perils of solar cell efficiency measurements. Nat Photon 6(6):337-340

56. Luber EJ, Buriak JM (2013) Reporting performance in organic photovoltaic devices. ACS Nano 7(6):4708-4714

57. Zimmermann E, Ehrenreich P, Pfadler T, Dorman JA, Weickert J, SchmidtMende L (2014) Erroneous efficiency reports harm organic solar cell research. Nat Photon 8(9):669-672

\section{Submit your manuscript to a SpringerOpen ${ }^{\circ}$ journal and benefit from:}

- Convenient online submission

- Rigorous peer review

- Open access: articles freely available online

- High visibility within the field

- Retaining the copyright to your article

Submit your next manuscript at $\boldsymbol{\nabla}$ springeropen.com 